\title{
Flow reactor synthesis of bio-based polyol from soybean oil for the production of rigid polyurethane
}

\section{foam}

Wei He ${ }^{a}$, Peng Kang ${ }^{b}$, Zheng Fang ${ }^{a,}{ }^{*}$, Jingying Hao ${ }^{c}$, Hao Wu ${ }^{a}$, Yuchen Zhu ${ }^{d}$, Kai Guo ${ }^{a, e, *}$

${ }^{\text {a }}$ College of Biotechnology and Pharmaceutical Engineering, Nanjing Tech University, Nanjing 211816, China

b SINOPEC Beijing Research Institute of Chemical Industry, Beijing 100013, China

c The Research Institute of SINOPEC Co. Ltd, Tianjin Branch, Tianjin 10000, China

d School of Pharmaceutical Sciences, Nanjing Tech University, Nanjing 211816, China

e State Key Laboratory of Materials-Oriented Chemical Engineering, Nanjing Tech University, Nanjing 210009, China

\section{Characterization}


The characteristic of bio-based polyols (acid number, oxirane value, viscosity, hydroxyl number) was analyzed according to ASTM D4662-08, AOCS Cd 9-57, ASTM D4878-08 and ASTM D4274-05, respectively.

Scanning electron microscope. The foam morphologies were obtained from an S-3400N scanning electron microscope. The sample was adhered to the copper platform after brittle fracture by liquid nitrogen. Then, the sample was observed after spraying gold under vacuum. The accelerating voltage was $20 \mathrm{kV}$.

Apparent foam density. The apparent foam density was determined in accordance with ASTM D1622-08. The volume of sample should be above $100 \mathrm{~cm}^{3}$. The precise volume and mass of samples should be determined accurately to calculate the apparent foam density.

Compression strength. Based on ASTM D1621-10, the compression strength was measured by using a CMT4204 wicket computer-controlled electronic universal testing machine. The test sample was cut with a dimension of $50 \mathrm{~mm} \times 50 \mathrm{~mm} \times 10 \mathrm{~mm}$. The vertical section of foaming was taken as the compression surface and fastened to electronic universal testing machine. The specimen was compressed at a rate of $10.0 \mathrm{~mm} / \mathrm{min}$. The test data was taken as the compression strength when the deformation amount reached $10 \%$. The results of three measurements were averaged.

Thermal conductivity. The test sample was cut with a dimension of $300 \mathrm{~mm} \times 300 \mathrm{~mm} \times 25$ mm. The sample was tested using an HFM 436 Lambda heat flow meter to determine thermal conductivity. The opposing surface temperature of the test sample was set to $13{ }^{\circ} \mathrm{C}$ and $23{ }^{\circ} \mathrm{C}$.

Dimensional stability. Based on ISO 2796: 1986, the dimensional stability of test sample was investigated. The test sample was cut with a dimension of $100 \mathrm{~mm} \times 100 \mathrm{~mm} \times 25 \mathrm{~mm}$. The 
sample was placed in room temperature for $24 \mathrm{~h}$. Then, it was moved into wet test chamber with constant temperature. The temperature was set to $70{ }^{\circ} \mathrm{C}$. The relative humidity was set to $95 \pm 5$ $\%$. The dimensions in five different positions were determined.

Thermogravimetrical analysis. By using a Pyris 1 thermogravimetric analyzer, the thermogravimetrical analysis of PUF was conducted under nitrogen atmosphere. The temperature range was $25-800{ }^{\circ} \mathrm{C}$. The heating rate was $10{ }^{\circ} \mathrm{C} / \mathrm{min}$. A disk $($ diameter $=15 \mathrm{~mm})$ with a thickness of $10 \mathrm{~mm}$ was cut from the PUF.

Dynamic thermomechanical analysis. The dynamic properties of the sample were measured using a dynamic mechanical analyzer. The storage modulus $\left(\mathrm{G}^{\prime}\right)$ and loss modulus $\left(\mathrm{G}^{\prime \prime}\right)$ were obtained at $1 \mathrm{~Hz}$ and $0.1 \%$ strain. The temperature range was $25-220^{\circ} \mathrm{C}$. The heating rate was 3 ${ }^{\circ} \mathrm{C} / \mathrm{min}$. 